\title{
Growth of a young pingo in the Canadian Arctic observed by RADARSAT-2 interferometric satellite radar
}

\author{
Sergey V. Samsonov ${ }^{1}$, Trevor C. Lantz ${ }^{2}$, Steven V. Kokelj ${ }^{3}$, and Yu Zhang ${ }^{1}$ \\ ${ }^{1}$ Canada Centre for Mapping and Earth Observation, Natural Resources Canada, 560 Rochester Street, Ottawa, ON, Canada \\ ${ }^{2}$ School of Environmental Studies, University of Victoria, Victoria, BC, Canada \\ ${ }^{3}$ Northwest Territories Geological Survey, Government of the Northwest Territories, Yellowknife, NWT, Canada
}

Correspondence to: Sergey V. Samsonov (sergey.samsonov@canada.ca)

Received: 3 November 2015 - Published in The Cryosphere Discuss.: 20 November 2015

Revised: 11 March 2016 - Accepted: 18 March 2016 - Published: 15 April 2016

\begin{abstract}
Advancements in radar technology are increasing our ability to detect Earth surface deformation in permafrost environments. In this paper we use satellite Differential Interferometric Synthetic Aperture Radar (DInSAR) to describe the growth of a large, relatively young pingo in the Tuktoyaktuk Coastlands. High-resolution RADARSAT2 imagery (2011-2014) analyzed with the Multidimensional Small Baseline Subset (MSBAS) DInSAR revealed a maximum $2.7 \mathrm{~cm} \mathrm{yr}^{-1}$ of domed uplift located in a drained lake basin. Satellite measurements suggest that this feature is one of the largest diameter pingos in the region that is presently growing. Observed changes in elevation were modeled as a $348 \times 290 \mathrm{~m}$ uniformly loaded elliptical plate with clamped edge. Analysis of historical aerial photographs suggested that ground uplift at this location initiated sometime between 1935 and 1951 following drainage of the residual pond. Uplift is largely due to the growth of intrusive ice, because the $9 \%$ expansion of pore water associated with permafrost aggradation into saturated sands is not sufficient to explain the observed short- and long-term deformation rates. The modeled thickness of ice-rich permafrost using the Northern Ecosystem Soil Temperature (NEST) was consistent with the maximum height of this feature. Modeled permafrost aggradation from 1972 to 2014 approximated elevation changes estimated from aerial photographs for that time period. Taken together, these lines of evidence indicate that uplift is at least in part a result of freezing of the sub-pingo water lens. Seasonal variations in the uplift rate seen in the DInSAR data closely match the modeled seasonal pattern in the deepening rate of freezing front. This study demonstrates that interferometric satellite radar can detect and contribute to understand-
\end{abstract}

ing the dynamics of terrain uplift in response to permafrost aggradation and ground ice development in remote polar environments. The present-day growth rate is smaller than predicted by the modeling and no clear growth is observed at other smaller pingos in contrast with field studies performed mainly before the 1990s. Investigation of this apparent discrepancy provides an opportunity to further develop observation methods and models.

\section{Introduction}

Pingos are conical ice-cored hills that grow in the permafrost environment (Mackay, 1998 and references within). There are over 11000 pingos in the world. Of these about 1350 are concentrated on the Tuktoyaktuk Coastal Plain in the western Canadian Arctic, 500 are located elsewhere in Canada, 1500 in Alaska, 6000 or more in Russia, and at least several hundred in the other parts of the world, such as Fennoscandia, Greenland, Spitsbergen, Mongolia, and Tibetan Plateau of China (Mackay, 1998; Wu et al., 2005; Grosse and Jones, 2011; Yoshikawa et al., 2013). Numerous near circular collapsed features interpreted as pingo remnants, most being of Holocene age, have been observed in former permafrost areas, such as Ireland, the United Kingdom, countries of Eastern Europe, and China (Jin et al., 2007). Pingo-like features have also been observed on Mars using the High Resolution Imaging Science Experiment (HiRISE) camera on board the Mars Reconnaissance Orbiter (Dundas et al., 2008; Burr et al., 2009; Soare et al., 2014). Understanding the genesis, growth, and collapse of pingos provides insight into the land- 

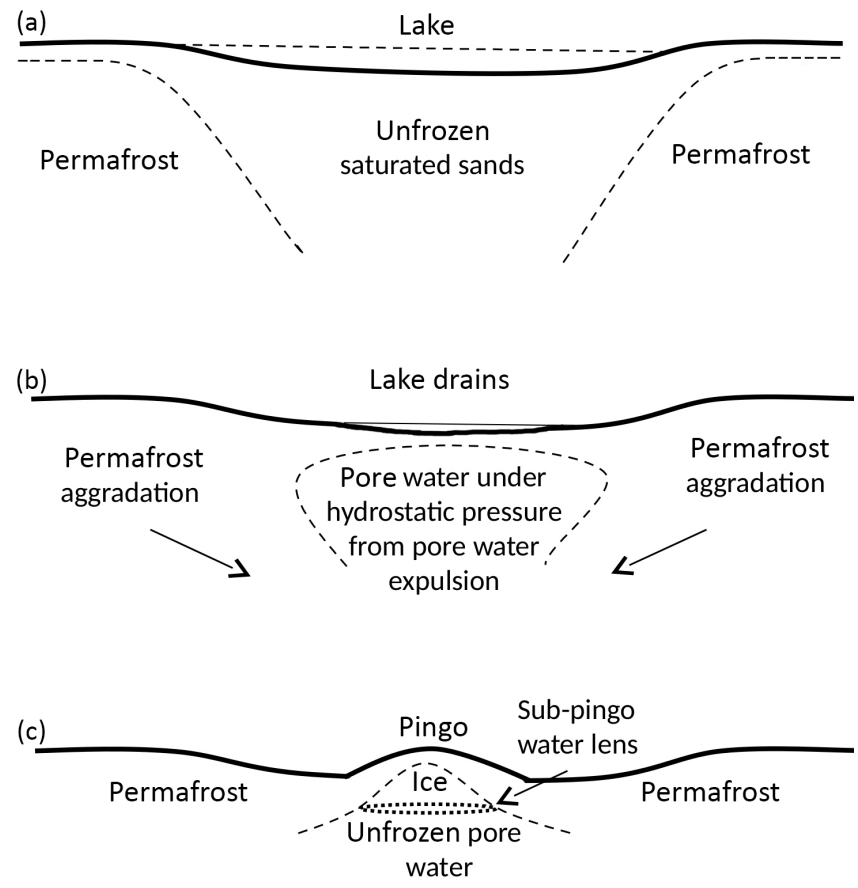

Figure 1. Growth of closed-system pingo (modified from Mackay (1998)): (a) lake underlain by basin of unfrozen saturated sands; (b) lake after rapid drainage, showing permafrost aggradation, pore water expulsion, and hydrostatic pressure increase beneath residual pond with thin layer of permafrost; (c) growing pingo underlain by sub-pingo water lens.

scape forming processes associated with permafrost aggradation and ground ice development on Earth, Mars, and possibly other planets. Seminal work by Dr. J. R. Mackay on genesis and growth of pingos has provided tremendous insight into the landscape forming processes associated with permafrost aggradation and ground ice development (e.g., Mackay, 1977, 1979, 1987, 1990, 1992, 1997, 1998). His research has provided context for our work, which explores the potential of SAR technology and processing techniques to describe surface deformation that would arise from processes associated with pingo growth.

The great majority (i.e., $\sim 98 \%$ ) of hydrostatic or closedsystem pingos develop in drained lake basins in association with permafrost aggradation in unfrozen saturated sandy lake sediments (Gurney, 1998; Mackay, 1998; Jones et al., 2011). Rapid lake drainage, caused either by coastal erosion or thermal erosion of ice wedges, exposes the lake bottom to subfreezing air temperatures (Fig. 1, Mackay, 1992). This initiates the process of permafrost aggradation into the unfrozen lake-bottom sediments. Downward aggradation of permafrost progresses at a rate inversely proportional to the square root of time (Freitag and McFadden, 1997). The water-ice phase transition produces $9 \%$ volume expansion, i.e., $V_{\mathrm{i}}=\frac{\rho_{\mathrm{w}}}{\rho_{\mathrm{i}}} V_{\mathrm{w}}=\frac{999.97}{916.70} V_{\mathrm{w}} \approx 1.09 V_{\mathrm{w}}$, where $\rho_{\mathrm{w}}, \rho_{\mathrm{i}}, V_{\mathrm{w}}$, and $V_{\mathrm{i}}$ are water and ice density and volume, respectively. During

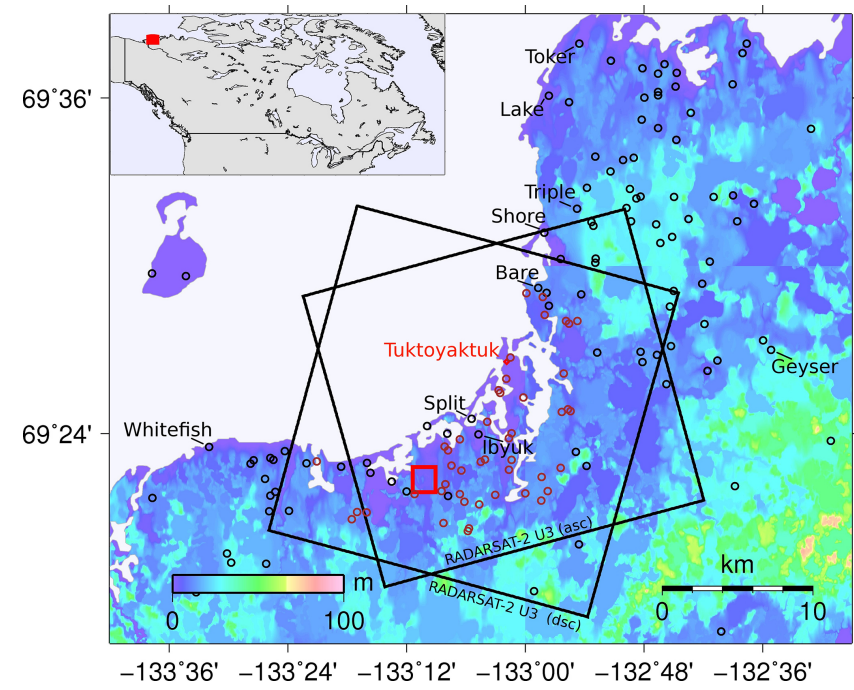

Figure 2. Study site located in Northwest Territories, Canada, is outlined in red. Background is a $90 \mathrm{~m}$ resolution digital elevation model (GeoGratis Web Services, Natural Resources Canada). Ascending and descending RADARSAT-2 Ultra-fine 3 (U3) frames are outlined in black. Black circles show locations of pingos identified on Canada Base Map (GeoGratis Web Services, Natural Resources Canada). Brown circles show locations of suspected pingos visually identified in high-resolution optical imagery. Names of known pingos are shown in black. Extent in top-left corner shows location of site in North America.

downward freezing of saturated sands, given free drainage, there will be little or no heave because of pore water expulsion and flow of water in the direction of lower pressure (Mackay, 1997). In a drained lake, expelled pore water typically flows to a residual pond, which is the usual site of pingo growth (Mackay, 1998). A closed system is formed when the residual pond freezes to the bottom. In this case, increasing pressure derived from pore water expelled during permafrost aggradation into the surrounding lake bottom can heave the relatively small area of thin permafrost beneath the residual pond to initiate pingo growth. If the addition of water to this location exceeds the rate of downward freezing, then a pressurized, sub-pingo water lens forms and heaves the pingo upward. Freezing of the pressurized water forms intrusive ice. If the water pressure drops due to the escape of water through a hydraulic fracture or a change in the ground water supply, segregated ice may form (Mackay, 1998).

Thick permafrost, sandy sediments, abundant lakes underlain by talik (i.e., unfrozen zones), and relatively frequent lake drainage contribute to the high concentration of pingos in the Tuktoyaktuk Coastlands (Fig. 2) (Mackay, 1998). The maximum thickness of lake ice in this region is about $2 \mathrm{~m}$, so lakes with greater depths are underlain by a talik (unfrozen sediments) (Mackay, 1998). The mean basal radius of most pingos is about $50 \mathrm{~m}$ while the maximum radius is typically less than $300 \mathrm{~m}$ (Mackay, 1979). Their heights vary between 
a few meters and approximately $55 \mathrm{~m}$, with a mean of $5 \mathrm{~m}$ (Grosse and Jones, 2011; Jones et al., 2011). Pingo basal area is typically established in the first few years of growth, determined primarily by characteristics of the residual pond where growth was initiated. Subsequently a pingo grows higher with a minimal increase in its basal area (Mackay, 1998). The long-term monitoring of numerous pingos by Mackay $(1977,1998)$ has shown that growth rates can vary significantly through time in response to changes in (1) rates of ground water flow to the sub-pingo water lens, (2) release of pressurized water along hydraulic fractures, and (3) variation in rates of downward freezing (Mackay, 1977, 1998). Pingo growth may continue as long as ground water continues to be supplied to the area beneath a pingo. It may take more than 1000 years for a talik to refreeze, so a pingo in the Tuktoyaktuk Coastlands may continue to grow for hundreds to thousands of years.

Previous studies of pingo growth and subsidence have been primarily based on annual or in some cases, shorter periods of more frequent field measurements of heights at benchmark locations and have required monumental field effort (Mackay, 1977, 1998). The subtle temporal changes of discrete topographic features such as pingos could not be easily detected by the early coarse-resolution Synthetic Aperture Radars, such as ERS-1/2, ENVISAT, or ALOS, that were capable of mapping large-scale ground deformation in permafrost areas (Liu et al., 2010; Chen et al., 2012, 2013). However, availability of high-resolution SAR data from the newer RADARSAT-2 satellite and advanced processing methodology allowed us to map a very largediameter pingo that has not been recognized by field investigations in the Tuktoyaktuk Coastlands and, for the first time, monitor intra-annual pingo growth rate with high temporal and spatial resolution over a period of 4 years.

\section{Data and processing methodology}

Historical aerial photographs, high-resolution Differential Interferometric Synthetic Aperture Radar (DInSAR) data, and field measurements were used to characterize the observed feature, located in the Tuktoyaktuk Coastlands, Northwest Territories, Canada.

\subsection{Differential Interferometric Synthetic Aperture Radar}

To map the growth of this feature 16 ascending and 20 descending Ultra-Fine 3 (U3) images with a spatial resolution of $1.6 \times 2.8 \mathrm{~m}$ and coverage of $20 \times 20 \mathrm{~km}$ (Table 1, Fig. 3) were acquired by the RADARSAT-2 satellite between June 2011 and September 2014 over the Tuktoyaktuk Coastlands. DInSAR processing was performed with GAMMA software (Wegmuller and Werner, 1997). The $3 \times 3$ spatial averaging (i.e., multilooking) in range and azimuth directions was
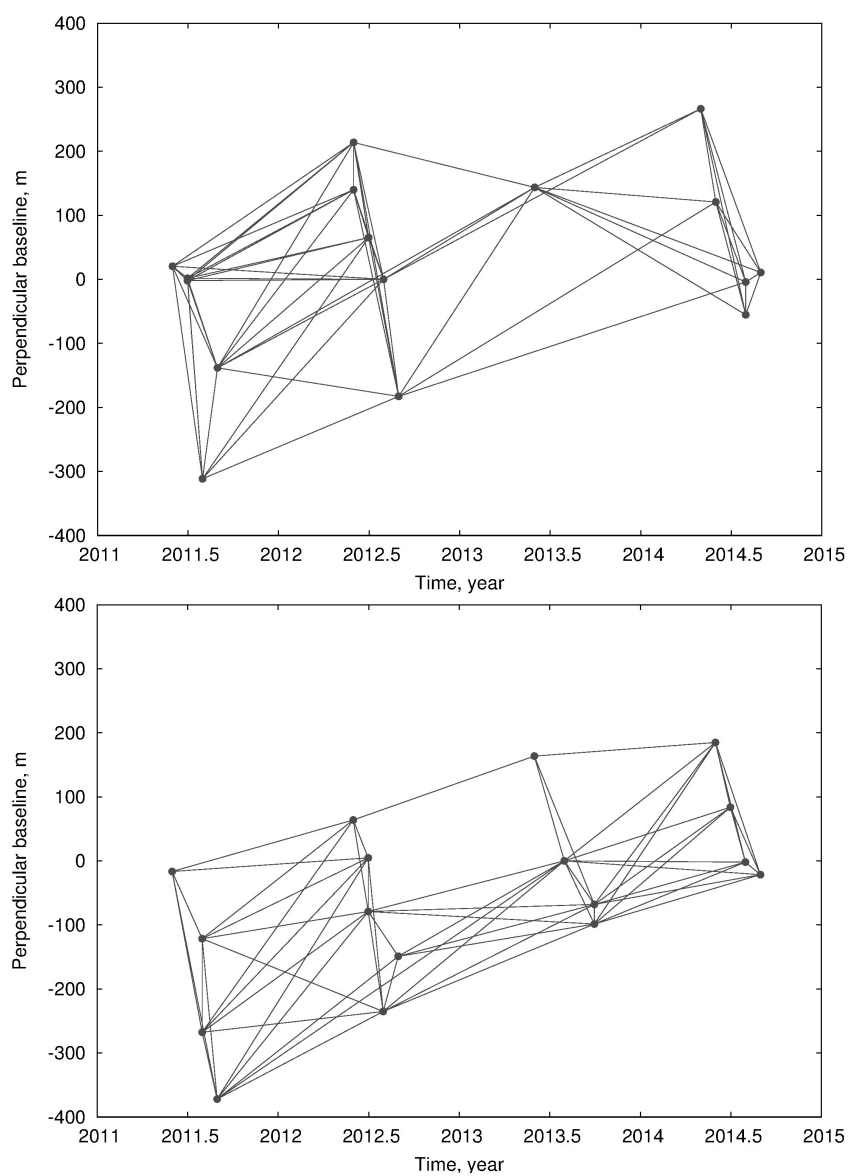

Figure 3. Perpendicular baseline and time span of ascending (top) and descending (bottom) interferograms used in this study. SAR acquisitions are marked as circles.

applied. A single master for each set was selected and remaining images were re-sampled into the master geometry. The topographic phase was removed using the $20 \mathrm{~m}$ resolution digital elevation model (DEM) (GeoGratis Web Services, Natural Resources Canada) with an approximate reported elevation accuracy of $5 \mathrm{~m}$. Differential interferograms were filtered using the adaptive filtering with filtering function based on local fringe spectrum (Goldstein and Werner, 1998) and unwrapped using the minimum cost flow algorithm (Costantini, 1998). The residual orbital ramp was observed in many interferograms and baseline refinement was performed to correct it. Minor interpolation of each interferogram was performed in order to increase the coverage reduced by decorrelation. This process is described in greater detail in Samsonov et al. (2011a). From 40 ascending and 64 descending highly coherent interferograms, the ascending and descending line-of-sight linear deformation rates were computed with the Small Baseline Subset (SBAS) algorithm (Samsonov et al., 2011b). Then, ascending and descending interferograms were geocoded and resampled to a common 
Table 1. RADARSAT-2 Ultra-Fine 3 (U3) Synthetic Aperture Radar images used in this study; $\theta$ is azimuth and $\phi$ is incidence angle, $N$ is number of images, and $M$ is number of interferograms computed for each data set. Time series span 19 June 2011-7 September 2014 interval when both ascending (asc) and descending (dsc) data are available.

\begin{tabular}{lccrrrr}
\hline DInSAR set & Orbit & Coverage & $\theta\left(^{\circ}\right)$ & $\phi\left(^{\circ}\right)$ & $N$ & $M$ \\
\hline RADARSAT-2, U3 & asc & $20110612-20140924$ & 344 & 32 & 16 & 61 \\
RADARSAT-2, U3 & dsc & $20110619-20140907$ & -165 & 32 & 17 & 62 \\
\hline Total & & $20110619-20140907$ & & 31 & 123 \\
\hline
\end{tabular}

lat/long grid with $\mathrm{GMT}^{1}$ scripts of a reduced spatial extent that covers only the study site with the uniform spatial sampling of $10 \mathrm{~m}$, and analyzed with the Multidimensional Small Baseline Subset (MSBAS) algorithm (Samsonov and d'Oreye, 2012; Samsonov et al., 2014):

$$
\left(\begin{array}{c}
\hat{\mathbf{A}} \\
\lambda \mathbf{L}
\end{array}\right)\left(\begin{array}{c}
\mathbf{V}_{\mathrm{E}} \\
\mathbf{V}_{\mathrm{U}}
\end{array}\right)=\left(\begin{array}{c}
\hat{\boldsymbol{\Phi}} \\
0
\end{array}\right)
$$

where matrix $\hat{\mathbf{A}}$ consists of time intervals between consecutive $\mathrm{SAR}$ acquisitions multiplied by east and up components of a line-of-sight vector; $\mathbf{V}_{\mathrm{E}}$ and $\mathbf{V}_{\mathrm{U}}$ represent unknown horizontal east-west and vertical velocities that are to be determined; $\hat{\boldsymbol{\Phi}}$ represents DInSAR data observed, geocoded, and resampled to a common grid; $\lambda$ is a regularization parameter; and $\mathbf{L}$ is a first-difference operator. Thus, MSBAS software computed vertical and horizontal deformation rates between consecutive acquisitions for each pixel by simultaneously processing ascending and descending DInSAR data. Deformation time series were then reconstructed from the computed deformation rates and the mean rate was estimated by fitting a straight line to the time series. Only the vertical deformation time series and the mean vertical deformation rate were used in further analysis.

\subsection{Historical aerial photographs}

To constrain the timing of the lake drainage event and to estimate long-term changes in elevation at this site, the following historical aerial photographs from the Natural Resources Canada Air Photo Library2 ${ }^{2}$ were analyzed: 1935 (A5023: 88R), 1951 (A12918: 092-093), 1972 (A22961: 029-030), and 2004 (A31864: 072-073). Summit Evolution Photogrammetric Workstation (DAT/EM, 2011) was used to create softcopy stereophoto models from 1972 and 2004 aerial photographs. The scale of these images allowed us to resolve differences in height of $\sim 0.5 \mathrm{~m}$. Absolute orientation was completed using a 2004 orthophoto from the Mackenzie Valley Airphoto Project ${ }^{3}$ supported by the Northwest Territories Centre for Geomatics, the government of the Northwest Territories, and a DEM provided by the National Topographic

\footnotetext{
${ }^{1}$ http://gmt.soest.hawaii.edu/

${ }^{2}$ https://neodf.nrcan.gc.ca/neodf_cat3/index.php

${ }^{3}$ http://apps.geomatics.gov.nt.ca/arcgis/rest/services/GNWT/ Elevation_LCC/MapServer/6
}

Service $^{4}$, Government of Canada. To estimate the elevation at 300 (1972) and 118 (2004) locations inside the former lake basin we used Summit Evolution's stereoplotter feature and DTM Collection tool to interface with ArcGIS and record coordinates and elevation values. These point data were interpolated to a continuous DEM for each time period using the Natural Neighbor tool in ArcGIS (version 10.1).

\subsection{Field measurements}

During a field visit in August 2014 this site was surveyed using a Nikon Nivo 5.M Total Station ${ }^{5}$, whose position was determined using resection from two benchmarks. The position of one of these benchmarks was determined using a Trimble R ${ }^{6}$ GNSS system. Post-processing the data from this static survey using Natural Resources Canada's Precise Point Positioning ${ }^{7}$ yielded a benchmark with an orthometric height of $4.388 \pm 0.001 \mathrm{~m}$. This point was used to correct the elevations obtained from the Total Station survey.

\section{Results: geodetic and field observations}

The DEM, RADARSAT-2 satellite data coverage, locations of known pingos from the Canada Base Map (GeoGratis Web Services, Natural Resources Canada), and suspected pingos visually identified in high-resolution optical imagery are shown in Fig. 2.

The observed elevated feature is located in the middle of a large drained lake basin (Fig. 4). The earliest available aerial photograph shows that in 1935 the study site was covered by a small pond (Fig. 4). By 1951, the pond was no longer visible and an area comparable with present conditions had been uplifted. This photographic evidence suggests that the growth of this feature began sometime between 1935 and 1951 following the drainage of the pond. This pond was located within a larger drained lake basin that drained at an unknown prior time. The DEMs computed from 1972, 2004,

\footnotetext{
${ }^{4}$ http://geogratis.gc.ca

${ }^{5}$ http://www.nikonpositioning.com

${ }^{6} \mathrm{http}: / /$ www.trimble.com

${ }^{7}$ http://www.nrcan.gc.ca/earth-sciences/geomatics/ geodetic-reference-systems/tools-applications/10925
} 

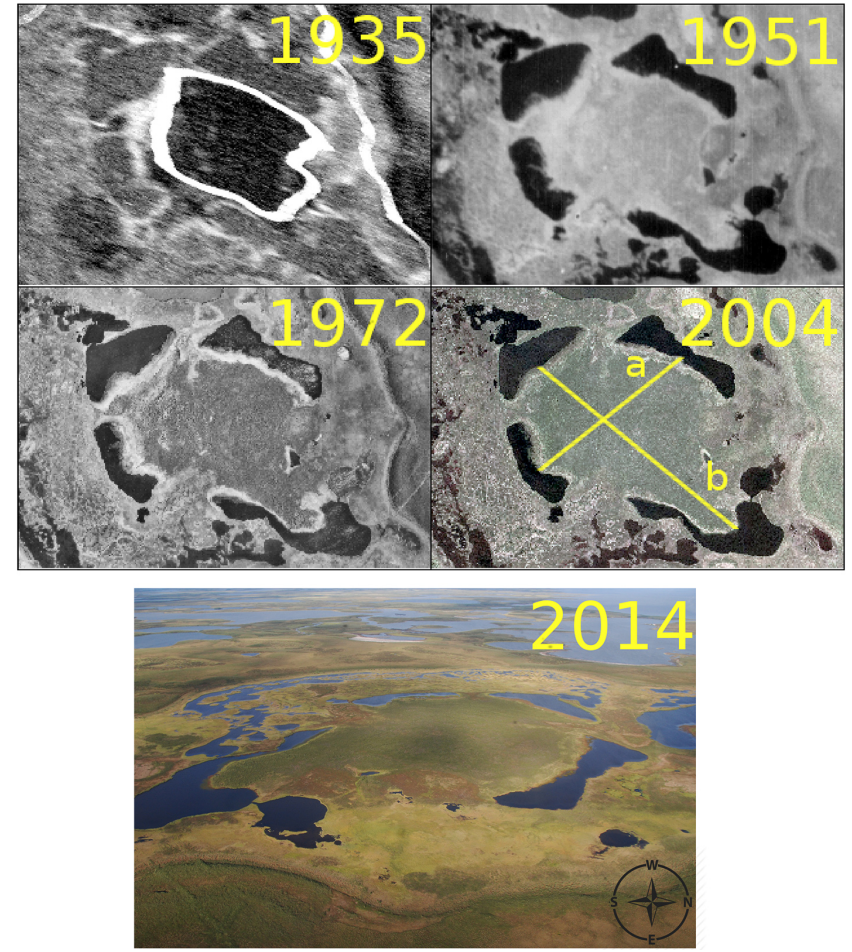

Figure 4. (Top) Historical aerial photographs of study site (National Air Photo Library, Natural Resources Canada) from 1935, 1950, 1972, and 2004 showing that the study site was occupied by a pond in 1935. For reference length of $a$ is $560 \mathrm{~m}$ and length of $b$ is $770 \mathrm{~m}$. (Bottom) Photograph of study site taken in August 2014 from helicopter (viewing from east).

and 2014 data (Fig. 5) show that elevation of this feature gradually increased from about $8 \mathrm{~m}$ in 1972 to $12 \mathrm{~m}$ in 2014 .

The ascending and descending line-of-sight linear deformation rates (Fig. 6) were calculated with the $2 \sigma$ measurement precision of 1.1 and $0.7 \mathrm{~cm} \mathrm{yr}^{-1}$, respectively. In spite of the presence of many known pingos in the area (black and brown circles in Figs. 2 and 6), the deformation pattern resembling the growth of a pingo was only observed at the study site outlined in red. This signal is particularly clear in the descending map, which was computed from a large set of 64 interferograms. Precision of the ascending map is lower due to the smaller number of available images, but it still fully confirms deformation signals observed in the descending map. The line-of-sight rates of an approximately similar magnitude were also observed by McCardle and Leighton (2013), which further supports the validity of our results. We could not detect uplift at other known pingos because of their size comparable to the spatial sampling of deformation products $(10 \mathrm{~m})$ and low-resolution DEM used to remove the topographic phase.

Vertical deformation time series from 2011 to 2014 calculated with MSBAS-DInSAR for the study site show maximum cumulative uplift of $9 \mathrm{~cm}$ over the 3.2-year time span
(Fig. 7). Over this period, the maximum annual linear rate of $2.7 \mathrm{~cm} \mathrm{yr}^{-1}$ was observed in the center of the feature (Fig. 8) and a mean uplift rate of the entire feature was $1.5 \mathrm{~cm} \mathrm{yr}^{-1}$. In order to better capture seasonal variability in the uplift rate, linear and harmonic functions were simultaneously fitted to the cumulative deformation time series:

$d(t)=A \sin \left(\frac{2 \pi}{T} t+\psi\right)+B t+C$,

where $d(t)$ is the cumulative deformation (uplift) measured in $\mathrm{cm}$ as a function of time $t$ defined in years since the beginning of the common era, $T$ is the period equal to 1 year, $A$ is the magnitude of the seasonal component equal to $0.4 \mathrm{~cm}$, $\psi$ is the phase at $t=0$ equal to 2.6 radian, $B$ is the linear rate equal to $2.6 \mathrm{~cm} \mathrm{yr}^{-1}$, and $C$ is the intercept equal to $-5190.6 \mathrm{~cm}$. The uplift rate was estimated by differentiation of the fitted function. The modeled seasonal uplift rate reaches maximum values in July and minimum values in February. Based on these observations this near-circular feature, approximately $500 \mathrm{~m}$ in diameter, was interpreted as a young pingo deforming the ground surface as a result of heave generated by the maintenance of a pressurized subpingo water lens and growth of intrusive and/or segregated ground ice.

\section{Deformation rate modeling}

In order to estimate the spatial and temporal patterns of uplift, vertical deformation rate was modeled by representing the pingo-like feature as an elastic uniformly loaded elliptical plate with a clamped edge (Timoshenko and WoinowskyKrieger, 1959):

$$
\begin{aligned}
& \Delta w=\Delta w_{0}\left(1-\frac{X^{2}}{a^{2}}-\frac{Y^{2}}{b^{2}}\right)^{2} \\
& \Delta w_{0}=\frac{\Delta q}{D} \frac{1}{\left(\frac{24}{a^{4}}+\frac{24}{b^{4}}+\frac{16}{a^{2} b^{2}}\right)} \\
& D=\frac{E h^{3}}{12\left(1-v^{2}\right)} \\
& X=x \cos \alpha+y \sin \alpha \\
& Y=-x \sin \alpha+y \cos \alpha,
\end{aligned}
$$

where $\Delta w$ is the observed annual deformation rate; $x, y$ and $X, Y$ are the spatial coordinates in geodetic and rotated coordinate systems; $a$ and $b$ are the semi-major and semi-minor axis; $\alpha$ is the tilt angle; $\Delta q$ is the annual rate of change in the effective driving upward pressure of sub-permafrost pore water; $E$ is Young's modulus; $h$ is the total thickness of the overburden and pingo ice; and $v$ is the Poisson ratio. Suitability of an elastic uniformly loaded circular plate model for describing the surface deformation associated with pingo growth and schematics was discussed in detail by Mackay (1987), and its schematic diagram can be found in Fig. 3 

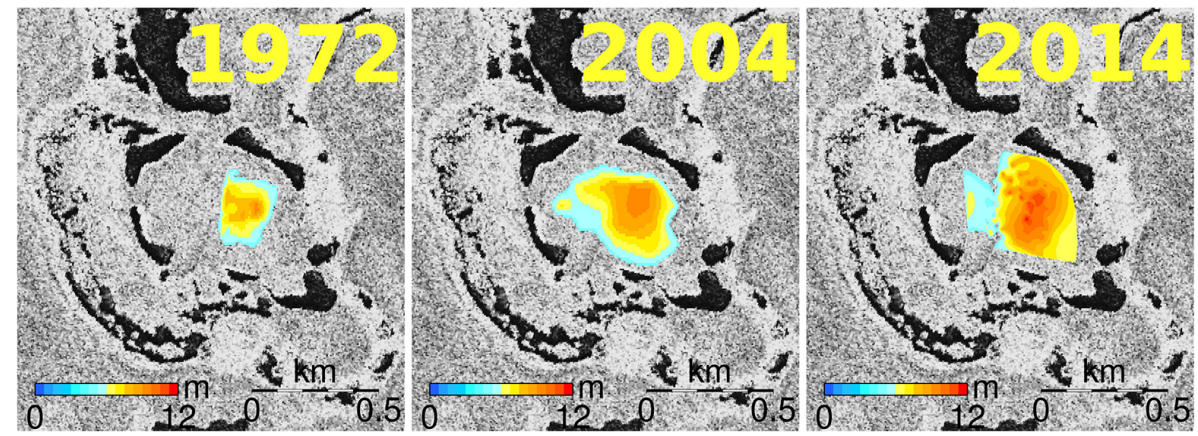

Figure 5. Elevation (> $5 \mathrm{~m}$ ) in 1972 and 2004 from stereo-photo analysis and in 2014 from Total Station surveys. Background is 14 August 2014 radar backscatter intensity.

Optimization based on simplex algorithm (Nelder and Mead, 1965) allowed estimation of the model parameters and their precision.

The best-fit model shown in Fig. 8 corresponds to an elliptical plate centered at $69.3728^{\circ} \mathrm{N}, 133.1688^{\circ} \mathrm{W}$ with semimajor and semi-minor axes of $348 \pm 2 \mathrm{~m}$ and $290 \pm 2 \mathrm{~m}$, tilted $27 \pm 3$ degrees clockwise, with magnitude of $\frac{\Delta q}{D}=$ $1.46 \pm 0.02 \times 10^{-10} \mathrm{~m}^{-3} \mathrm{yr}^{-1}$. Assuming the total thickness of the overburden and pingo ice $h$ ranges from 11 to $22 \mathrm{~m}$ (from NEST modeling for pingo $(11 \mathrm{~m})$ and non-pingo $(22 \mathrm{~m})$ scenarios, see below), Young's modulus $E$ ranges from 0.8 to 3.5 GPa (Schmeltz et al., 2002; Yang et al., 2015), and Poisson's ratio $v$ equals 0.4 , the pressure increase $\Delta q$ ranges from 15 to $540 \mathrm{~Pa} \mathrm{yr}^{-1}$, which is sufficient to uplift the ice column by $0.2-6.0 \mathrm{~cm} \mathrm{yr}^{-1}$. The observed average uplift rate of $1.5 \mathrm{~cm} \mathrm{yr}^{-1}$ is within this range. The quantity $\frac{\Delta q}{D}$ was measured with the precision of $\sim 1 \%$.

\section{Permafrost aggradation modeling}

The growth of a pingo is due to downward freezing of a pressurized sub-pingo water lens (Mackay, 1979). Permafrost aggradation into the sub-adjacent lake bottom sediments and pore water expulsion continue to feed the sub-pingo water lens. The process of permafrost aggradation both maintains a pressurized water lens and, beneath the pingo, converts the water into ice. Thus, we can estimate the growth rate of a pingo based on the downward freezing of the water in the sub-pingo water lens. An increase in thickness of the pingo ice corresponds to its uplift and, over time, increases the lag between seasonal cooling cycles and permafrost aggradation at depth, and pingo growth. To approximate long-term change in the thickness of ice and the growth rates of pingos, Mackay (e.g., 1979, 1998) applied a simplified Stefan solution (Ingersoll et al., 1954) with a 1-year time step. In this study, we used the Northern Ecosystem Soil Temperature (NEST) model (Zhang et al., 2003) to investigate the longterm patterns and rates of permafrost aggradation, total permafrost thickness, and the associated ground uplift. NEST is a one-dimensional process-based transient permafrost model that considers the effects of climate, vegetation, snow, and soil conditions on ground thermal dynamics based on energy and water transfer through the soil-vegetation-atmosphere system (Zhang et al., 2003). Ground temperature is calculated by solving the one-dimensional heat conduction equation. The upper boundary condition (the ground surface or snow surface when snow is present) is determined based on the surface energy balance, and the lower boundary condition (at a depth of $120 \mathrm{~m}$ ) is defined based on the geothermal heat flux $\left(0.09 \mathrm{~W} \mathrm{~m}^{-2}\right)$. The thickness of the snowpack is determined based on snow density and the amount of snow on the ground (water equivalent), calculated as the cumulative difference between snowfall and snowmelt. The profile of snow density is simulated considering compaction and destructive metamorphism. Soil water dynamics are simulated considering water input (rainfall and snowmelt), output (evaporation and transpiration), and distribution among soil layers. Soil thawing and freezing, and associated changes in fractions of ice and liquid water, are determined based on energy conservation. The NEST model has been tested and applied at different scales to predict thermal conditions for areas across Canada (Zhang et al., 2005, 2006, 2008, 2012, 2014). A more detailed description of the model can be found in Zhang et al. (2003).

In this study NEST is used to model two scenarios. The first scenario (pingo scenario) models permafrost aggradation involving growth of near pure ice. This scenario provides an analogue for the growth of pingo ice over a pressurized sub-pingo water lens, which is assumed to be continuously supplied with expelled pore water from permafrost aggradation in the surrounding sediments (Fig. 1) (Mackay, 1977). In this scenario we assumed that ground materials consist of a saturated material with $99 \%$ porosity to represent a growing ice core over a sub-pingo water lens. As the model was developed for terrestrial conditions, we used saturated porous material to represent sub-pingo water lens. The freezing of this water results in the growth of pingo ice. Given these assumptions and a reasonable approximation for the date of pingo inception, the modeled thickness of permafrost growth 


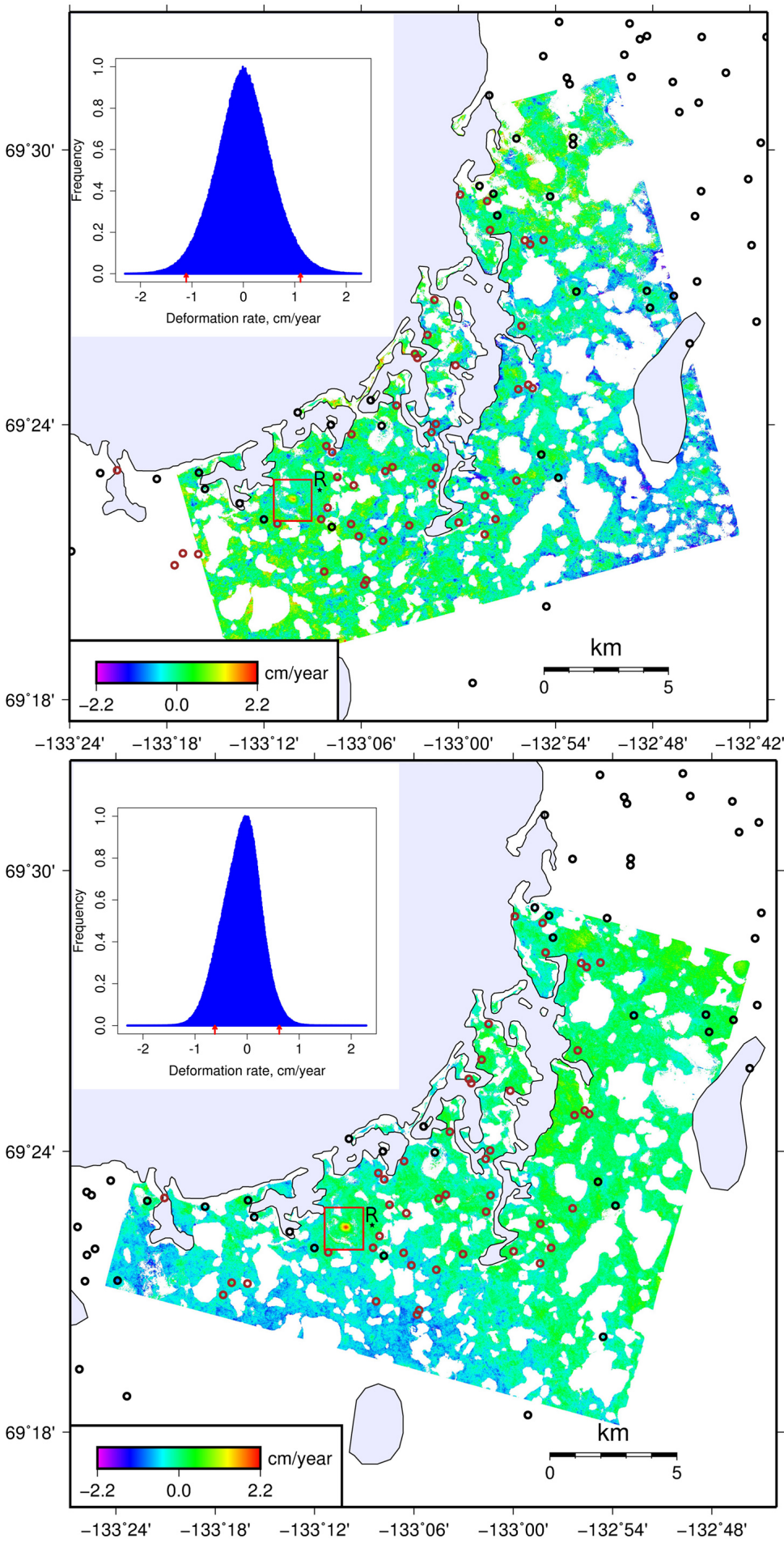

Figure 6. Line-of-sight linear deformation rate during 2011-2014 period computed from ascending (top) and descending (bottom) RADARSAT-2 U3 imagery. Study site is outlined in red. Black circles show locations of known pingos from Canada Base Map (GeoGratis Web Services, Natural Resources Canada). Brown circles show locations of suspected pingos visually identified in high-resolution optical imagery. Decorrelated areas are shown in white. $R$ is reference region. Extents in top-left corner show deformation rate histograms with red arrows marking $95 \%$ confidence interval. 


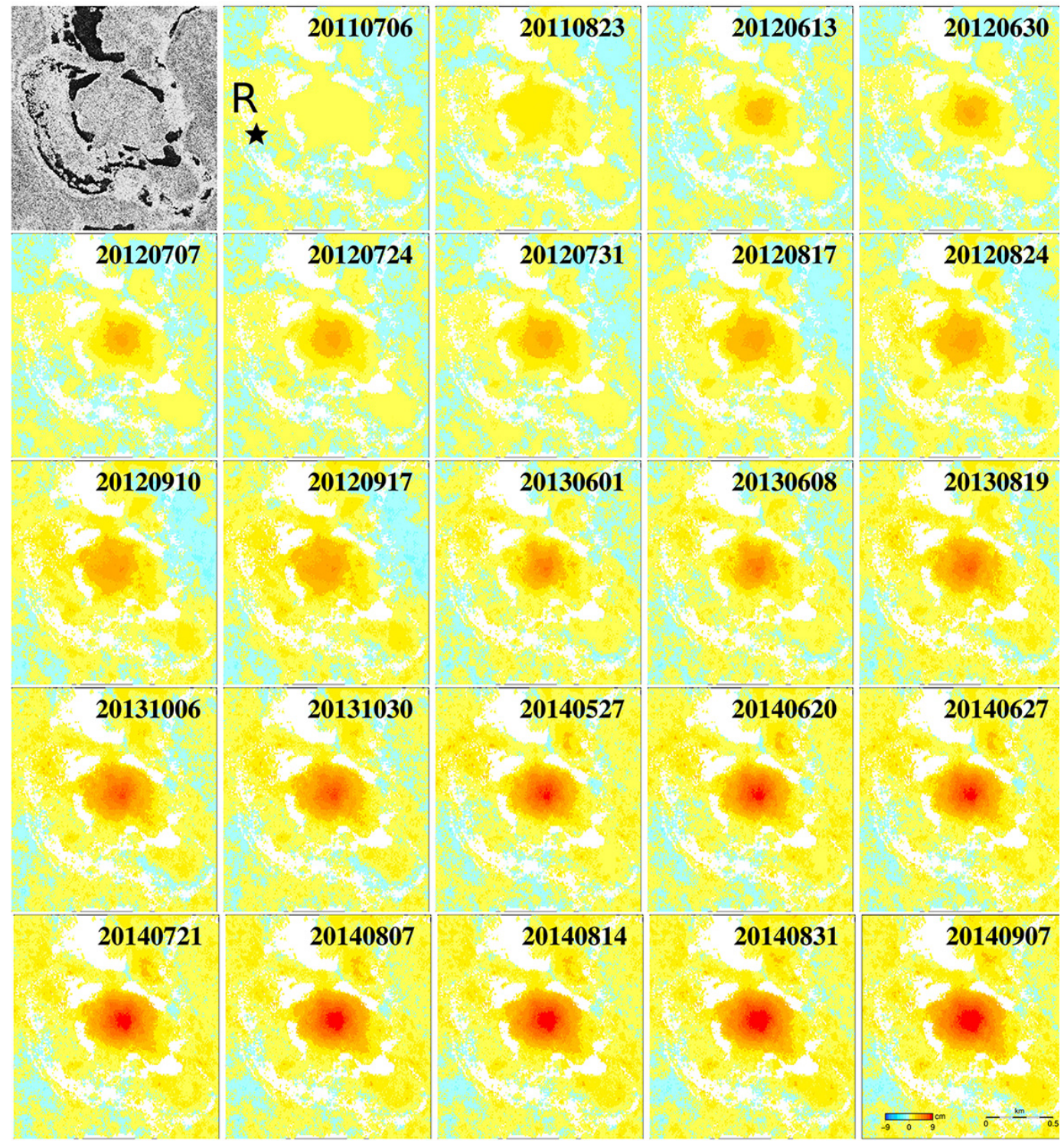

Figure 7. Selected images of vertical ground deformation time series during 19 June 2011-7 September 2014 computed from ascending and descending RADARSAT-2 data using Multidimensional Small Baseline Subset (MSBAS) technique. Decorrelated areas are shown in white. $R$ is reference region. Gray image shows 14 August 2014 radar backscatter intensity.

as near pure ice should approximate maximum height of the feature.

The second scenario models the aggradation of permafrost into saturated sand without the development of pingo ice (non-pingo scenario). In this case ground materials consist of saturated sand with $33 \%$ porosity. In both scenarios we assumed that the residual pond drained and permafrost aggradation began in 1940. However, since we do not know the exact date when the residual pond drained, we also ran the model for the two scenarios using start dates of 1930 and 1950. Here we note that we also do not know when the larger basin (within which the pingo developed) drained.
The model input data of daily air temperature and precipitation were compiled from observations at Tuktoyaktuk weather station (about $10 \mathrm{~km}$ away from the study site and observations began in 1948) with gaps filled based on observations at Inuvik (about $115 \mathrm{~km}$ away from the study area). Before 1948, the climate data were filled using the data from 1960 to 1967 . Vapor pressure was estimated using daily minimum air temperature and daily solar radiation was estimated based on latitude, day of year, and diurnal temperature range (Zhang et al., 2012). For the pingo scenario, the model was initialized using a ground temperature typical for a drained lake bottom of $4{ }^{\circ} \mathrm{C}$ (Mackay, 1987). For the non-pingo sce- 


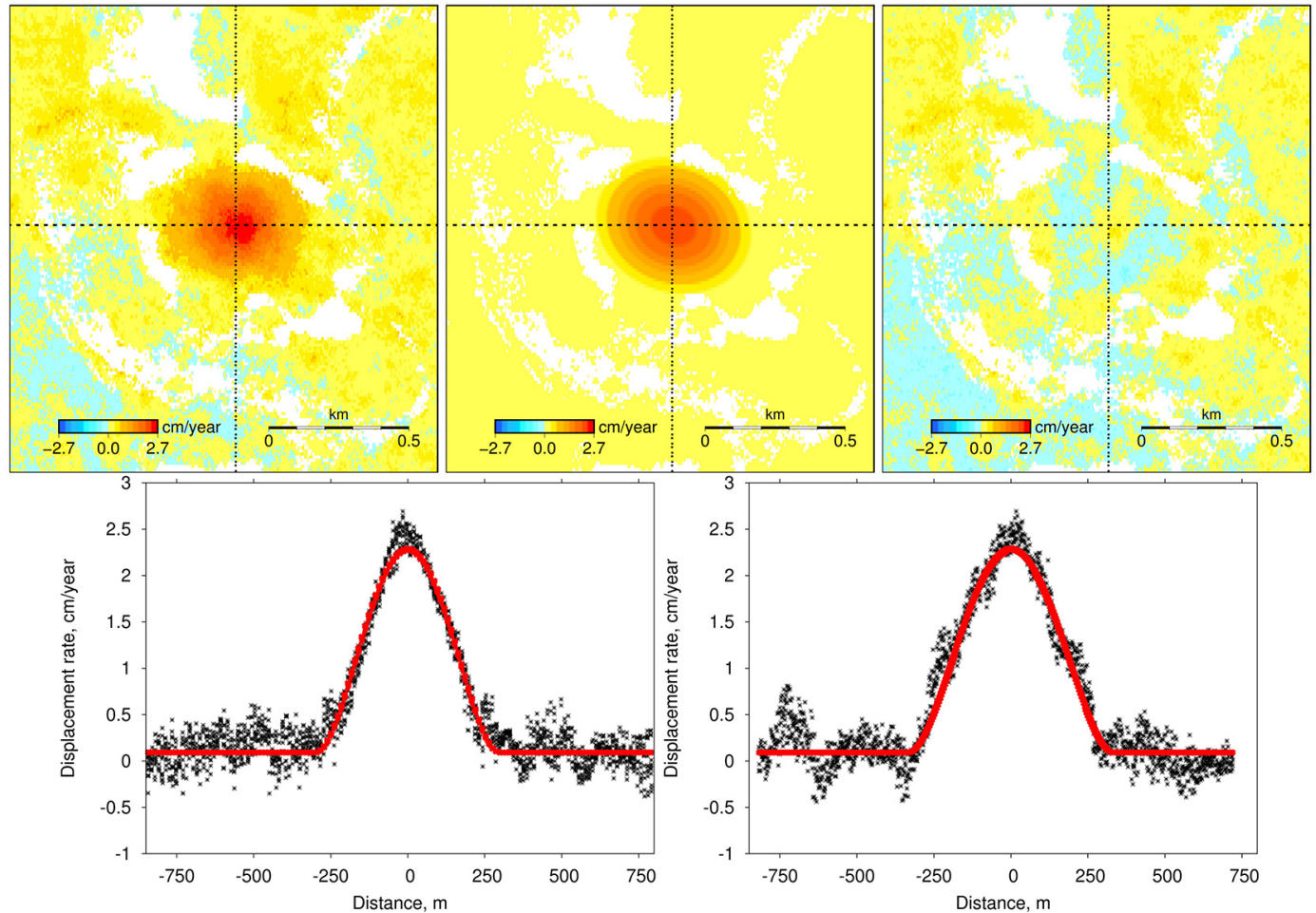

Figure 8. (Top) Observed data, model, and residual of vertical linear deformation rate. Decorrelated areas are shown in white. Best-fit model corresponds to ellipse located at $69.3728^{\circ} \mathrm{N}, 133.1688^{\circ} \mathrm{W}$ with semi-major and semi-minor radii of $348 \pm 2 \mathrm{~m}$ and $290 \pm 2 \mathrm{~m}$, tilted $27 \pm 3^{\circ}$ clockwise, with a magnitude of $\frac{\Delta q}{D}=1.46 \pm 0.02 \times 10^{-10} \mathrm{~m}^{-2}$. (Bottom) Latitudinal and longitudinal profiles across uplifting area. Observed data are plotted in black; modeled data are plotted in red.

nario, the model was initialized using the climate data in 1960 , a typical climate year of the area.

\subsection{Modeling results}

In the pingo scenario, the modeled thickness of permafrost was $10.7(9.9-11.2) \mathrm{m}$ by the end of 2014, which is very similar to the maximum relief of the observed feature $(12 \mathrm{~m})$ (Fig. 5). The modeled growth of ice thickness from 19722014 was 3.8 (3.6-4.3) $\mathrm{m}$, which is comparable to the $4 \mathrm{~m}$ of vertical heave that occurred over that time period. The modeled growth rate of ice thickness during 2011-2014 was 7.4 $(7.1-8.0) \mathrm{cm} \mathrm{yr}^{-1}$, which is larger than the satellite-observed maximum uplift rate $\left(2.7 \mathrm{~cm} \mathrm{yr}^{-1}\right)$.

In the non-pingo scenario, the modeled freezing front was at the depth of $22.6 \mathrm{~m}$ by the end of 2014 . The $9 \%$ volume expansion due to freezing of soil pore water to a modeled depth of $22.6 \mathrm{~m}$ produced $0.67(0.61-0.71) \mathrm{m}$ of uplift by the end of 2014. This is much smaller than the actual height of the observed feature (12 m) (Fig. 5). Similarly, uplift during 1972-2014 was only $0.24(0.22-0.27) \mathrm{m}$, which is much smaller than the $4 \mathrm{~m}$ of vertical heave observed during that period. The maximum uplift rate during 2011-2014 was only $0.46(0.43-0.50) \mathrm{cm} \mathrm{yr}^{-1}$, which is much smaller than the observed maximum uplift rate of $2.7 \mathrm{~cm} \mathrm{yr}^{-1}$ (Fig. 8).
The time series of the modeled permafrost aggradation rates (i.e., deepening rates of the freezing front), air temperature, and DInSAR observed uplift rates for the 2011-2014 period are shown in Fig. 9. After 7 decades of permafrost aggradation, the pingo (ice) and non-pingo (saturated sand) modeling scenarios showed a slower deepening rate of the freezing front in February and April in comparison to a more rapid rate of deepening in July and October (Fig. 9), respectively. Due to a lag in the downward propagation of the winter cooling wave, the freezing front at depth descends faster in summer than winter. The 10-year difference in the model initiation time resulted in a less than $10 \%$ difference in the depths of the freezing front and less than a month of phase shift.

The satellite-observed seasonal uplift rate reaches peak values in late July (red dashed line in Fig. 9), which coincides with the annual maximum rate of downward permafrost growth as predicted by the NEST model for the pingo scenario. Active-layer thaw in summer typically yields surface settlement in areas of permafrost terrain. These DInSAR results suggest that the seasonal pattern of satellite-observed land uplift is likely driven by increased water pressure beneath the pingo and subsequent freezing of the water lens. In order to produce the observed rate of uplift during the 2011-2014 monitoring period, and a height increase of $4 \mathrm{~m}$ 

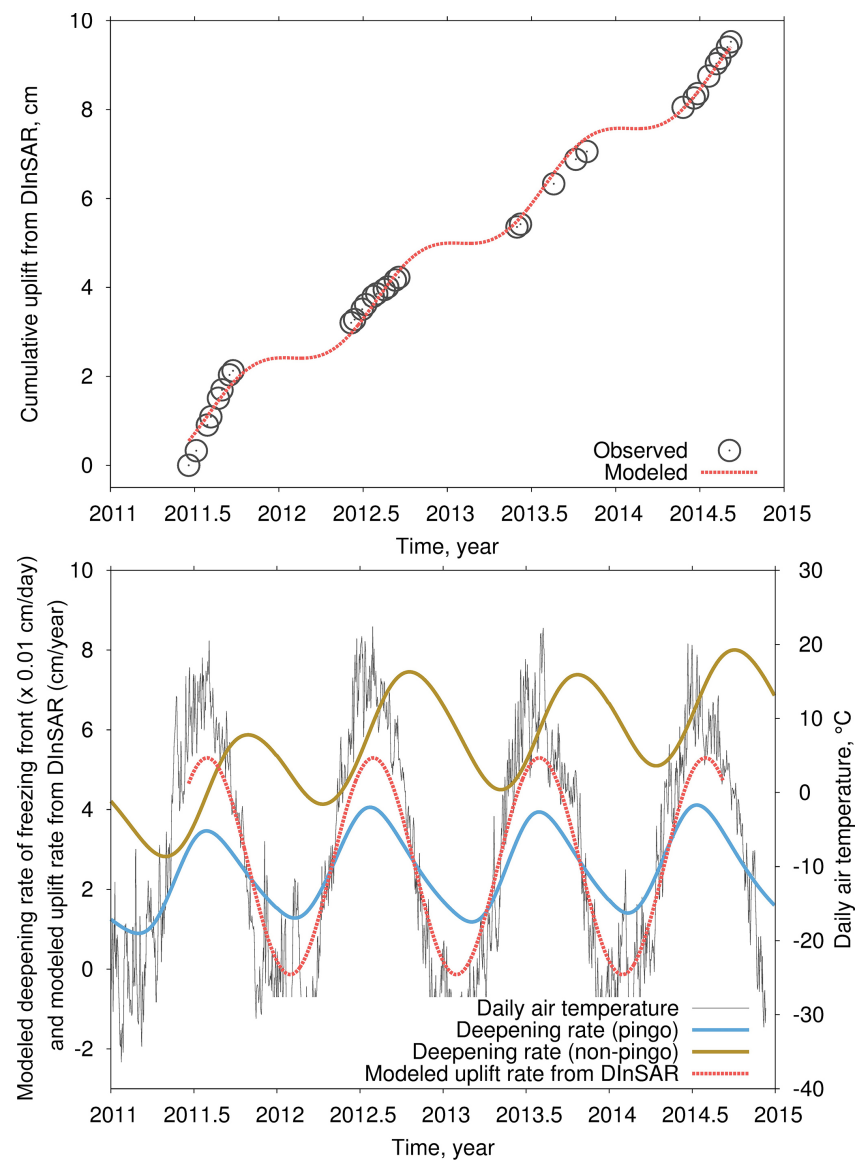

Figure 9. (Top) Observed and modeled (according to Eq. 2) uplift time series for area experiencing maximum uplift and (bottom) modeled deepening rate of freezing front for pingo (blue line) and non-pingo (brown line) scenarios assuming drainage of residual pond in 1940, modeled (according to Eq. 2) uplift rate (red dashed line), and mean daily air temperature observed at Tuktoyaktuk weather station located $10 \mathrm{~km}$ northeast from the study site (gray line). Acceleration of uplift is observed in July when deepening rate of freezing front is greatest and air temperature reaches annual maximum.

during 1972-2014, permafrost aggradation must have been accompanied by the pore water expulsion from the surrounding areas and the growth of intrusive and/or segregated ice beneath the pingo feature. It is likely that pressure conditions beneath the growing pingo feature are not always conducive to growth of intrusive ice, so that downward aggradation of permafrost beneath the pingo is yielding both lens ice and pore ice (Mackay, 1979). Since the basin within which the pingo is growing may have drained long before 1940, the rate of permafrost aggradation we model in sands may not represent the current rate of permafrost aggradation into the surrounding drained lake basin.

\section{Discussion and conclusions}

The relief and size of this feature, in conjunction with observed rates of deformation suggest that uplift has occurred at least in part due to presence of a sub-pingo water lens and growth of intrusive ice. For this to occur, pore water expelled by permafrost aggrading into the surrounding drained lake basin must be sustaining a sub-pingo water lens. Permafrost aggradation into saturated sands and pore water expulsion would maintain a pressurized sub-pingo water lens to enable growth of intrusive ice and heave of the ground surface, consistent with the common growth mechanism of hydrostatic pingos in Tuktoyaktuk Coastlands (Mackay, 1998).

Although significant attention has been given to climate warming and permafrost degradation in the Arctic regions, landscape forming processes associated with permafrost aggradation and ground ice development are still very important. In spite of a large number (i.e., > 11 000) of pingos on Earth their intra-annual growth has never been detected by satellite radar interferometry. Previous studies of pingo dynamics were largely based on annual or semi-annual field observations performed over a long period of time (Mackay, 1998). Since the size of most pingos is comparable to the spatial resolution of early SAR sensors their dynamics could not have been easily detected by such sensors. Seasonal land cover changes (i.e., vegetation growth, snow cover) further complicated interferometric analysis. The availability of high-resolution satellite radar data and novel processing techniques, coupled with field validation, provides new opportunities to study the dynamics of pingos and other permafrost processes associated with ground ice development and degradation at high temporal and spatial resolutions. Here we have demonstrated that DInSAR data allow discrimination of ground movements characteristic of processes involved in pingo development.

Historical aerial photographs, field measurements, and modeling suggest that the satellite-detected feature is an actively growing pingo that developed over a residual pond in a large drained lake basin. We show that the uplift of the ground at this location initiated sometime between 1935 and 1951 following drainage of the residual pond and is caused at least in part by the growth of intrusive ice, because the $9 \%$ expansion of pore water during permafrost aggradation in saturated sands with no free drainage would generate insufficient heave to explain the observed short- and long-term deformation rates. The estimated rates and patterns of uplift determined by DInSAR are within the range of conditions measured by Mackay (1998) during the long-term study of numerous growing pingos in the study region. Thermal modeling of permafrost growth involving the freezing of a water lens indicated that modeled thickness of ice growth from 1940 to 2014 is comparable with the maximum height of this feature. Similarly, the modeled thickness of ice growth from 1972 to 2014 is comparable with changes in elevation of the feature estimated from aerial photographs. Patterns of vari- 
ation in the uplift rate seen in the DInSAR data also match the modeled seasonal change in the deepening rate of freezing front. Seasonal changes in the rate of pingo ice growth have also been inferred from alternating clear and bubble rich bands of pingo ice (Mackay, 1990). The model of a pingo as an elastic uniformly loaded elliptical plate with clamped edge provided a good fit to the observed feature. The location and semi-major and semi-minor radii of the modeled feature are $69.3728^{\circ} \mathrm{N}, 133.1688^{\circ} \mathrm{W}$ and $348 \pm 2 \mathrm{~m}$ and $290 \pm 2 \mathrm{~m}$. Our observations indicate that this pingo is one of the largest (diameter) actively growing pingos in this region. DInSAR could also be used for studying other known pingos, pingo remnants, and pingo-like features throughout remote circumpolar regions and potentially on other planets, such as Mars. Future monitoring of this and other ground-ice-related landforms by interferometric satellite radar, which can yield highresolution spatial and temporal data, can complement fieldbased investigations and contribute to a better understanding of permafrost-related processes, including the impact of climate change.

This analysis of ground deformation in the Tuktoyaktuk Coastlands (Fig. 6) only shows active deformation, clearly resembling pingo growth, at one single site. However, earlier field measurements performed by Mackay (1998) showed that many of the smaller pingos in the Tuktoyaktuk Coastlands are actively growing. The majority of RADARSAT2 interferograms used in this study were contaminated by various sources of noise, including decorrelation caused by seasonal changes and snow cover, atmospheric disturbances, and residual orbital ramps, which resulted in reduced precision. However, a few interferograms acquired in ideal conditions (i.e., small spatial baseline, frozen ground, no snow) were of an exceptionally high quality. In these interferograms no active deformation processes of similar spatial extent and magnitude were observed except for the pingo studied here. The discrepancy between long-term field measurements and these results is likely caused by the inability of our processing methodology to resolve deformation at smaller spatial scales. It is recommended to use a high-resolution DEM for removing the topographic phase for improving DInSAR spatial resolution and, in future, to integrate field-based monitoring as a part of calibrating and validating remote sensing results.

\section{The Supplement related to this article is available online at doi:10.5194/tc-10-799-2016-supplement.}

Acknowledgements. We would like to acknowledge field assistance provided by Abra Martin, Ciara Sharpe, Robin Felix, Doug Panaktalok, and Pierre Berube. Assistance with mapping was provided by Rebecca Segal. Funding support for this project was provided by the NWT Cumulative Impact Monitoring Program, government of the Northwest Territories, the Natural Science and Engineering Research Council, the Canada Foundation for Innovation, Polar Knowledge Canada S\&T Program (project 1516-186), and NWT Geological Survey contribution no. 96. Post-processing was performed and figures were plotted with R, GMT, and GNUPLOT software. RADARSAT-2 Data and Products ${ }^{\circledR}$ MacDONALD, DETTWILER AND ASSOCIATES LTD. (2011-2014) - all rights reserved. RADARSAT is an official mark of the Canadian Space Agency. We thank C. R. Burn and N. Short for their valuable comments on an earlier version of this manuscript. Comments from anonymous reviewers improved the quality of this manuscript.

Edited by: T. Zhang

\section{References}

Burr, D., Tanaka, K., and Yoshikawa, K.: Pingos on Earth and Mars, Planet. Space Sci., 57, 541-555, doi:10.1016/j.pss.2008.11.003, 2009.

Chen, F., Lin, H., Li, Z., Chen, Q., and Zhou, J.: Interaction between permafrost and infrastructure along the Qinghai-Tibet Railway detected via jointly analysis of C- and L-band small baseline SAR interferometry., Remote Sens. Environ., 123, 532540, doi:10.1016/j.rse.2012.04.020, 2012.

Chen, F., Lin, H., Zhou, W., Hong, T., and Wang, G.: Surface deformation detected by ALOS PALSAR small baseline SAR interferometry over permafrost environment of Beiluhe section, Tibet Plateau, China, Remote Sens. Environ., 138, 10-18, 2013.

Costantini, M.: A novel phase unwrapping method based on network programming, IEEE T. Geosci. Remote Sens., 36, 813-821, 1998.

DAT/EM: Summit Evolution Digital Stereoplotter Professional Edition and Feature Collection Edition Operation Manual, DAT/EM Systems International, Anchorage, Alaska, Tech. rep., 2011.

Dundas, C., Mellon, M., McEwen, A., Lefort, A., Keszthelyi, L., and Thomas, N.: HiRISE observations of fractured mounds: Possible Martian pingos, Geophys. Res. Lett., 35, L04201, doi:10.1029/2007GL031798, 2008.

Freitag, D. and McFadden, T.: Introduction to Cold Regions Engineering, ASCE Publications, 758 pp., 1997.

Goldstein, R. and Werner, C.: Radar interferogram filtering for geophysical applications, Geophys. Res. Lett., 25, 4035-4038, 1998.

Grosse, G. and Jones, B.: Spatial distribution of pingos in northern Asia, The Cryosphere, 5, 13-33, doi:10.5194/tc-5-13-2011, 2011.

Gurney, S.: Aspects of the genesis and geomorphology of pingos: perennial permafrost mounds, Prog. Phys. Geogr., 22, 307-324, 1998.

Ingersoll, L., Zobel, O., and Ingersoll, A.: Heat conduction: with engineering, geological and otherapplications, Madison University of Wisconsin Press, Madison, 325 pp., 1954.

Jin, H., Chang, X., and Wang, S.: Evolution of permafrost on the Qinghai-Xizang (Tibet) Plateau since the end of the late Pleistocene, J. Geophys. Res., 112, F02S09, doi:10.1029/2006JF000521, 2007.

Jones, B., Grosse, G., Hinkel, K., Arp, C., Walker, S., Beck, R., and Galloway, J.: Assessment of pingo distribution and morphometry using an IfSAR derived digital surface model, western Arc- 
tic Coastal Plain, Northern Alaska, Geomorphology, 138, 1-14, doi:10.1016/j.geomorph.2011.08.007, 2011.

Liu, L., Zhang, T., and Wahr, J.: InSAR measurements of surface deformation over permafrost on the North Slope of Alaska, J. Geophys. Res., 115, F03023, doi:10.1029/2009JF001547, 2010.

Mackay, J.: Pulsating pingos, Tuktoyaktuk Peninsula, N.W.T., Can. J. Earth Sci., 14, 209-222, doi:10.1139/e77-023, 1977.

Mackay, J.: Pingos of the Tuktoyaktuk Peninsula Area, Northwest Territories, Geogr. Phys. Quat., 33, 3-61, 1979.

Mackay, J.: Some mechanical aspects of pingo growth and failure, western Arctic coast, Canada, Can. J. Earth Sci., 24, 1108-1119, 1987.

Mackay, J.: Seasonal growth bands in pingo ice, Can. J. Earth Sci., 27, 1115-1125, 1990.

Mackay, J.: Arctic ecosystems in semi-arid regions: Implications for resource management, Lake stability in an ice-rich permafrost environment: examples from the western Arctic coast., 1-25, Environment Canada, Saskatoon, Sask, NHRI Symposium Series 7, 1992.

Mackay, J.: A full-scale field experiment (1978-1995) on the growth of permafrost by means of lake drainage, western Arctic coast: a discussion of the method and some results, Can. J. Earth Sci., 34, 17-33, doi:10.1139/e17-002, 1997.

Mackay, J.: Pingo growth and collapse, Tuktoyaktuk Peninsula Area, Western Arctic Coast, Canada: A long-term field study, Geogr. Phys. Quat., 3, 271-323, 1998.

McCardle, A. and Leighton, J.: Remote sensing in the Arctic, presentation in: Pan-Territorial permafrost workshop, Yellowknife, NWT, Canada, 2013.

Nelder, J. and Mead, R.: A simplex method for function minimization, Comp. J., 7, 308-313, 1965.

Samsonov, S. and d'Oreye, N.: Multidimensional time series analysis of ground deformation from multiple InSAR data sets applied to Virunga Volcanic Province, Geophys. J. Int., 191, 1095-1108, doi:10.1111/j.1365-246X.2012.05669.x, 2012.

Samsonov, S., Beavan, J., Gonzalez, P., Tiampo, K., and J., F.: Ground deformation in the Taupo Volcanic Zone, New Zealand observed by ALOS PALSAR interferometry, Geophys. J. Int., 187, 147-160, 2011a.

Samsonov, S., van der Koij, M., and Tiampo, K.: A simultaneous inversion for deformation rates and topographic errors of DInSAR data utilizing linear least square inversion technique, Comp. Geosci., 37, 1083-1091, 2011b.

Samsonov, S., d'Oreye, N., González, P., Tiampo, K., Ertolahti, L., and Clague, J.: Rapidly accelerating subsidence in the Greater Vancouver region from two decades of ERS-ENVISATRADARSAT-2 DInSAR measurements, Remote Sens. Environ., 143, 180-191, doi:10.1016/j.rse.2013.12.017, 2014.

Schmeltz, M., Rignot, E., and MacAyea, D.: Tidal flexure along icesheet margins: comparison of InSAR with an elastic-plate model, Ann. Glaciol., 34, 202-208, 2002.
Soare, R., Conway, S., Dohm, J., and El-Maarry, M.: Possible opensystem (hydraulic) pingos in and around the Argyre impact region of Mars, Earth Planet. Sc. Lett., 398, 25-36, 2014.

Timoshenko, S. and Woinowsky-Krieger, S.: Theory of Plates and Shells, (Engineering Societies Monographs), McGraw-Hill Book Company, Inc., 580 pp., 1959.

Wegmuller, U. and Werner, C.: GAMMA SAR processor and interferometry software, in: The 3rd ERS symposium on space at the service of our environment, Florence, Italy, 14-21, 1997.

Wu, Z., Barosh, P., Hu, D., Wu, Z., Peisheng, Y., Qisheng, L., and Chunjing, Z.: Migrating pingos in the permafrost region of the Tibetan Plateau, China and their hazard along the Golmud-Lhasa railway, Eng. Geol., 79, 267-287, doi:10.1016/j.enggeo.2005.02.003, 2005.

Yang, Z., Still, B., and Ge, X.: Mechanical properties of seasonally frozen and permafrost soils at high strain rate, Cold Reg. Sci. Technol., 113, 12-19, doi:10.1016/j.coldregions.2015.02.008, 2015.

Yoshikawa, K., Sharkhuu, N., and Sharkhuu, A.: Groundwater hydrology and stable isotope analysis of an open-system pingo in Northwestern Mongolia, Permafrost Periglac., 24, 175-183, 2013.

Zhang, Y., Chen, W., and Cihlar, J.: A process-based model for quantifying the impact of climate change on permafrost thermal regimes, J. Geophys. Res., 108, 4695, doi:10.1029/2002JD003354, 2003.

Zhang, Y., Chen, W., Smith, S., Riseborough, D., and Cihlar, J.: Soil temperature in Canada during the twentieth century: complex responses to atmospheric climate change, J. Geophys. Res., 110, D03112, doi:10.1029/2004JD004910, 2005.

Zhang, Y., Chen, W., and Riseborough, D.: Temporal and spatial changes of permafrost in Canada since the end of the Little Ice Age, J. Geophys. Res., 111, D22103, doi:10.1029/2006JD007284, 2006.

Zhang, Y., Chen, W., and Riseborough, D.: Disequilibrium response of permafrost thaw to climate warming in Canada over 1850-2100, Geophys. Res. Lett., 35, L02502, doi:10.1029/2007GL032117, 2008.

Zhang, Y., Li, J., Wang, X., Chen, W., Sladen, W., Dyke, L., Dredge, L., Poitevin, J., McLennan, D., Stewart, H., Kowalchuk, S., Wu, W., Kershaw, G. P., and Brook, R.: Modelling and mapping permafrost at high spatial resolution in Wapusk National Park, Hudson Bay Lowlands, Canad. J. Earth Sci., 49, 925-937, doi:10.1139/E2012-031, 2012.

Zhang, Y., Olthof, I., Fraser, R., and Wolfe, S.: A new approach to mapping permafrost and change incorporating uncertainties in ground conditions and climate projections, The Cryosphere, 8, 2177-2194, doi:10.5194/tc-8-2177-2014, 2014. 